\title{
Canadian Recommendations for Clinical Trials of Pharmacologic Interventions in Rheumatoid Arthritis: Inclusion Criteria and Study Design
}

\author{
JACOB KARSH, EDWARD C. KEYSTONE, BOULOS HARAOUI, J. CARTER THORNE, JANET E. POPE, \\ VIVIAN P. BYKERK, WALTER P. MAKSYMOWYCH, MICHEL ZUMMER, WILLIAM G. BENSEN, \\ MAJED M. KRAISHI, and members of the Canadian Rheumatology Research Consortium
}

\begin{abstract}
Objective. Current clinical trial designs for pharmacologic interventions in rheumatoid arthritis (RA) do not reflect the innovations in RA diagnosis, treatment, and care in countries where new drugs are most often used. The objective of this project was to recommend revised entry criteria and other study design features for RA clinical trials.

Methods. Recommendations were developed using a modified nominal group consensus method. Canadian Rheumatology Research Consortium (CRRC) members were polled to rank the greatest challenges to clinical trial recruitment in their practices. Initial recommendations were developed by an expert panel of rheumatology trialists and other experts. A scoping study methodology was then used to examine the evidence available to support or refute each initial recommendation. The potential influence of CRRC recommendations on primary outcomes in future trials was examined. Recommendations were finalized using a consensus process.

Results. Recommendations for clinical trial inclusion criteria addressed measures of disease activity [Disease Activity Score 28 using erythrocyte sedimentation rate (DAS28-ESR) $>3.2$ PLUS $\geq 3$ tender joints using 28-joint count (TJC28) PLUS $\geq 3$ swollen joint (SJC28) OR C-reactive protein $(\mathrm{CRP})$ or ESR $>$ upper limit of normal PLUS $\geq 3$ TJC28 PLUS $\geq 3$ SJC28], functional classification, disease classification and duration, and concomitant RA treatments. Additional recommendations regarding study design addressed rescue strategies and longterm extension.

Conclusion. There is an urgent need to modify clinical trial inclusion criteria and other study design features to better reflect the current characteristics of people living with RA in the countries where the new drugs will be used. (First Release July 15 2011; J Rheumatol 2011;38:2095-2104; doi:10.3899/jrheum.110188)
\end{abstract}

Key Indexing Terms:

RHEUMATOID ARTHRITIS CLINICAL TRIALS METHODOLOGY ELIGIBILITY

The randomized controlled trial (RCT) is the standard for drug evaluation used by regulatory agencies and bodies deciding on drug reimbursement, such as the Canadian Agency for Drugs and Technologies in Health (CADTH) and the National Institute for Health and Clinical

From The Canadian Rheumatology Research Consortium.

Supported by The Canadian Rheumatology Research Consortium.

J. Karsh, MDCM, FRCPC, Professor of Medicine, Division of

Rheumatology, University of Ottawa, Department of Medicine, Ottawa

Hospital, Ottawa, Ontario; E.C. Keystone, MD, FRCPC, Professor of

Medicine, University of Toronto, Director, Rebecca MacDonald Centre for

Arthritis and Autoimmune Diseases, Mount Sinai Hospital, Toronto,

Ontario; B. Haraoui, MD, FRCPC, Associate Professor, Department of

Medicine, Université de Montréal, Centre Hospitalier de l'Université de

Montréal, Montreal, Quebec; J.C. Thorne, MD, FRCPC, Head, Division

of Rheumatology, Southlake Regional Health Centre, Newmarket,

Ontario; J.E. Pope, MD, MPH, FRCPC, Professor, Department of

Medicine, University of Western Ontario, Rheumatology Division, St.

Joseph's Health Care, London, Ontario; Mount Sinai Hospital, Rebecca

MacDonald Centre for Arthritis and Autoimmunity; V.P. Bykerk, MD,

FRCPC, Mount Sinai Hospital, Rebecca MacDonald Centre for Arthritis
Excellence (NICE) in the United Kingdom. Coincident with the reliance on well-executed RCT has been a considerable decline in recruitment in established sites with clinical trial experience and a shift to sites in countries with less developed medical research infrastructure ${ }^{1,2,3}$. Concerns regard-

and Autoimmunity; Harvard University, Cambridge, Massachusetts, USA; W.P. Maksymowych, FRCPC, FACP, FRCP(UK), Professor, Department of Medicine, University of Alberta, Edmonton, Scientist, Alberta Heritage Foundation for Medical Research; M. Zummer, MD, FRCPC,

Associate Professor, University of Montreal, Chef, Rhumatolgie, $\mathrm{CH}$ Maisonneuve-Rosemont, Montreal, Quebec; W.G. Bensen, MD, FRCPC, Clinical Professor, McMaster University, St. Joseph's Hospital, Hamilton, Ontario; M.M. Kraishi, MB, BCh, FRCPC, Clinical Professor of Medicine (Rheumatology), Memorial University of Newfoundland, Newfoundland and Labrador, Canada; Medical Director (Rheumatology), Nexus Clinical Research.

Address correspondence to Dr. J. Karsh, The Ottawa Hospital, Riverside Campus, 1967 Riverside Drive, Ottawa, ON K1H 7W9, Canada.

E-mail: jkarsh@ottawahospital.on.ca

Full Release Article. For details see Reprints/Permissions at jrheum.org Accepted for publication May 12, 2011. Personal non-commercial use only. The Journal of Rheumatology Copyright (c) 2011. All rights reserved. 
ing research proficiency in sites with less clinical trial expertise are reflected in the variability in efficacy results and placebo response rates that have been observed global$1 y^{4,5,6,7}$. Additional challenges include the ability to collect informed consent from illiterate and vulnerable populations, and the ethics of testing drugs that will not be available to the host nation once the study is completed ${ }^{4,5}$. Because of these factors there is an increasing concern that the globalization of clinical trials may impede the development of new therapies, not only in rheumatology, but across many diseases.

In rheumatology, substantial variation in the incidence of infectious adverse events has been observed from country to country, and this has influenced the withdrawal of new drugs $^{8}$. There is also evidence demonstrating that differences in baseline characteristics of patients with rheumatoid arthritis (RA) globally are related to the economic wealth of countries $^{9,10,11,12,13,14}$. As a result, RA populations in developing countries have a much higher level of RA disease activity than those in wealthier countries. This disparity calls into question the generalizability of research findings from studies where most participants have been recruited from developing countries, a point that is not lost on regulatory agencies or payers 1,5 .

The globalization of clinical trials was in response to several factors including increasing costs and bureaucratic challenges in North America and Western Europe ${ }^{1,15}$. Trial design is also affected by ethical and methodological requirements in countries that adhere to the International Conference on Harmonization guidelines for clinical trials of pharmaceuticals for human use ${ }^{16}$. However, the need remains to test new therapies for RA. This can be facilitated by changing trial inclusion and exclusion criteria to better reflect the characteristics of RA populations in the countries where the drugs will most often be used.

The Canadian Rheumatology Research Consortium (CRRC) is a network of rheumatology trialists and other experts from across Canada. CRRC members have seen unprecedented changes in the clinical trials arena over the past decade. Earlier diagnosis and access to biologics in North America and Europe, coupled with the common use of higher doses of methotrexate (MTX), limits patient eligibility for trials. In addition, markers of disease activity for many patients have decreased overall, yet inclusion criteria for many trials continue to require high numbers of tender and swollen joints and high eligibility limits for laboratory values. This creates a critical situation by greatly reducing the number of Canadian patients enrolled in the studies that will be used to provide evidence to inform the availability and access to therapies and guide overall rheumatology care in Canada.

In the context of this dynamic international environment, the CRRC undertook a study to inform recommendations for the entry criteria and other design considerations to be used in clinical trials in RA.

\section{MATERIALS AND METHODS}

The CRRC recommendations were developed using a modified nominal group consensus method ${ }^{17}$. CRRC members were polled using a questionnaire to rank the greatest challenges to clinical trial recruitment in their practices. A followup questionnaire was administered (with a very limited response period) to collect additional information about problematic trial eligibility criteria. Initial recommendations were developed by an expert panel of rheumatology trialists and other experts affiliated with the CRRC. A scoping study methodology was then used to examine the evidence available to support or refute each initial recommendation ${ }^{18}$. Key steps are outlined in Table 1 . The potential effects of CRRC recommendations on primary outcomes in future trials were considered. We examined the primary outcome variables from RCT using similar inclusion criteria to determine if there was any significant influence on expected short-term and longterm outcomes for American College of Rheumatology (ACR) response ${ }^{19}$, European League Against Rheumatism (EULAR) response ${ }^{20}$, and radiographic progression. Recommendations were finalized using a consensus process.

\section{RESULTS}

There are 63 CRRC members representing 38 distinct clinical sites. Twenty-eight sites (74\%) completed the initial questionnaire, which addressed overall challenges to clinical trial recruitment. Fifteen of 63 (24\%) CRRC members completed a followup questionnaire specifically targeting trial entry criteria. The low response rate is attributed to the limited response window, as it was circulated just prior to the 1-day workshop. Ten Canadian rheumatologists participated on the expert panel and prepared preliminary recommendations, reviewed current literature, and participated in the final consensus process. Resulting recommendations for study inclusion criteria addressed measures of disease activity and previous and concomitant RA treatments. Additional recommendations regarding study design features that may affect patient recruitment were also identified. Issues related to the limitations of traditional and current clinical trial design and RA outcomes and endpoints were the subject of much discussion and are the focus of a current CRRC scoping study. Along with the specific recommendations to improve trial recruitment, evidence-informed discussion points have been reported where appropriate.

Inclusion and exclusion criteria.

Confirmed diagnosis of RA. Recommendation: (future) clinical trials should use the 2010 ACR and EULAR classification criteria for RA.

The ACR and EULAR have collaborated to devise new RA classification criteria to replace the existing RA classification criteria ${ }^{21,22}$. The 2010 RA classification criteria will not affect the inclusion of patients with established RA but may be important for studies of interventions for early RA to ensure the homogeneity of study populations. New analyses with these criteria have demonstrated that increased numbers of patients qualify as RA and this will enhance recruitment, and given weighting on seropositivity, will likely increase specificity of disease at entry ${ }^{23}$.

Disease activity. Recommendation: (a) (At the least) moderate disease at baseline defined by a Disease Activity Score 28 using erythrocyte sedimentation rate (DAS28-ESR) $>3.2$ 
Table 1. Scoping study methodology used to inform Canadian recommendations for entry criteria and study design features of clinical trials of pharmacologic interventions in rheumatoid arthritis (RA).

Expert panel convened

Needs assessment

Priority questions identified and preliminary recommendations developed

Literature search

Relevance screening

Data extraction

Key informant input

Data review

CRRC recommendations finalized
Ten Canadian rheumatologists with expertise in the design and implementation of Phase I to IV clinical trials of pharmacologic treatments for RA and/or other inflammatory diseases

Survey of 63 CRRC members (representing 38 clinical sites) to determine and rank challenges to clinical trial recruitment in their practices. Results discussed and prioritized in a 1-day workshop Preliminary recommendations addressed eligibility criteria and study design. Inclusion criteria: disease activity and duration (DAS, TJC, SJC, APR, functional classification, disease duration), concurrent conditions (laboratory abnormalities, infections, tuberculosis screening and treatment), previous and concurrent RA medications, methotrexate, other DMARD and oral corticosteroids at baseline, washout period, number of prior conventional DMARD, prior biologics. Study design: rescue, intraarticular steroid rescue, longterm extension, timing of study visits

A systematic search of Medline, Embase, and Cochrane Central Register of Controlled Trials to September 2010 was carried out by research support staff using search strategies designed by research librarians. The search strategy included MeSH terms, keywords, and text words related to RA and RCT of DMARD and biologic treatment. To supplement these electronic bibliographic databases, abstracts from annual scientific meetings were also searched (ACR and EULAR). Additional literature considered for this project included very recent diagnosis and treatment guidelines (published later than 2008), systematic reviews and metaanalyses, longitudinal cohorts, and postmarketing surveillance or registry data. Recent critical reviews and narrative reviews by experts in the field were also considered Independent review of abstracts by research support team. Inclusion criteria included: population (RA), drug (DMARD and/or biologics for RA), primary and secondary outcomes reported. Quality assessment is not completed in a scoping study

Reports from relevant studies were pulled. For RCT, the following variables were extracted: first author, year, trial acronym, phase, investigational agent, control agent, eligibility criteria for: disease activity and duration inclusion criteria, concurrent conditions, previous and concurrent RA medications, rescue (including joint injection), timing of primary outcome, ACR response, EULAR response, and radiographic progression for the experimental and control group(s) at all timepoints reported

Key informants were asked to identify any additional literature or current research that should be included in the scoping study Data were reviewed by the Expert Panel and preliminary recommendations were revised

Consensus method used to finalize CRRC recommendations.

Recommendations to be vetted by the international rheumatology community and other stakeholders

ACR: American College of Rheumatology; APR: acute-phase reactants; CRRC: Canadian Rheumatology Research Consortium; DAS: Disease Activity Score; DMARD: disease-modifying antirheumatic drug; EULAR: European League Against Rheumatism; RA: rheumatoid arthritis; RCT: randomized controlled trial; SJC: swollen joint count; TJC: tender joint count.

PLUS 3 or more tender joints using the 28 -joint count $(\geq 3$ TJC28) PLUS 3 or more swollen joints using the 28-joint count ( $\geq 3$ SJC28), OR, (b) C-reactive protein (CRP) greater than upper limit of normal ( $>$ ULN) according to the centralized reference laboratory OR ESR $>$ ULN using a licensed independent laboratory PLUS $\geq 3$ TJC28 PLUS $\geq 3$ SJC28.

Entry criteria for RA RCT have traditionally included a specific number of tender joints (TJ) and swollen joints (SJ) using the 68/66 joint count and specified levels for acute-phase reactants (APR). Recent changes include the move to the 28 -joint count as used by the DAS ${ }^{24}$ and a baseline DAS28 to set the disease activity entry criterion ${ }^{25,26,27}$. Kingsley, et $a l^{28}$ have demonstrated that the DAS28 may better identify trial-ready patients in clinical cohorts. The use of specific cutoff criteria for ESR and/or CRP is being reconsidered. There is mounting evidence that APR levels

Personal non-commercial use only. The Journal of Rheumatology Copyright (c) 2011. All rights reserved. 
may not be elevated in many patients, normal ranges may be declining in those who are diagnosed and treated early with conventional disease-modifying antirheumatic drugs (DMARD), and levels may not change at all in some patients despite the effectiveness of treatment ${ }^{29,30,31,32}$. The new EULAR/ACR revised RA classification criteria ${ }^{22}$ do not contain specific laboratory values, but instead use normal and abnormal ratings as determined by local laboratory standards. The terminology "elevated ESR or CRP" without a value specified is starting to be used in RCT and takes into account the differences in laboratory reference rates ${ }^{33}$. The CRP can be processed in a centralized laboratory, which is particularly important for international RCT. To improve reliability, we recommend that ESR not be done in the office of the investigator, rather that they be read by a licensed local independent laboratory. Differences in DAS28 classifications using ESR vs CRP have recently been examined $^{34,35}$. The DAS28 using CRP has not been validated for use in RCT. There is sufficient evidence from recent clinical trials that using a CRP $\geq 1 \mathrm{mg} / \mathrm{dl}$ or $\geq \mathrm{ULN}$ and ESR $\geq \mathrm{ULN}$ has not affected the ability to achieve a significant clinical or radiographic outcome $33,36,37,38,39,40,41,42,43,44,45,46,47$.

Another challenge to trial recruitment in recent years is the significant reduction of actively inflamed joints seen in patients in usual care. In a cross-sectional analysis of $3 \mathrm{RA}$ cohorts at 3 timepoints, contemporary cohorts had smaller numbers of tender and swollen joints ${ }^{48}$. In Canada, the Canadian Early Arthritis Cohort (CATCH) is a recently established cohort of adults with early RA. In a recent analysis of 886 patients in $\mathrm{CATCH}$, the median TJC28 and SJC28 was 2 at 12 weeks from consult (when patients would first be approached for RCT), and after therapy initiation (CATCH investigators, personal communication). A subanalysis was recently completed to examine cohort eligibility for $312 \mathrm{CATCH}$ patients receiving MTX, assessed at 6 months after initiation of treatment. The authors report that reducing joint criteria from 6 to 4 of 28 joints (in combination with elevated APR vs absolute cutoff criteria) resulted in a $25 \%$ increase in eligible patients; $40 \%$ of these subjects would be trial-eligible ${ }^{49}$. Greenberg, et $a l^{50}$ recently used the 28 -joint validation study by Smolen, et $a l^{51}$ to estimate equivalents for 66-joint count thresholds and mapped 6 of 66 active joints to 4 of 28 active joints to determine the trial readiness of 2 US cohorts for biologics trials. While our recommendation is based on an estimation to the equivalent of 6 active joints using a 66 -joint $\operatorname{count}^{50}$, there are now published examples of RA RCT that specified very low active joint counts ( $<6$ on either the 66 -joint count or 28 -joint count) at baseline $6,37,52,53,54,55$. Zhang, et $a l^{56}$ have recently analyzed the data from 6 multicenter trials $(\mathrm{N}=2002)$ and determined that subtrials of subjects with lower TJC had much higher sensitivity to change than those of subjects with higher TJC across all trials and outcome measures (results were not consistent for SJC subgroups). The concordance of the DAS28 with other recommended criteria for joint activity and APR is highlighted in the following example. A patient with a TJC of 3, SJC of 3, ESR $18 \mathrm{~mm} / \mathrm{h}$, and a patient global assessment of $30 / 100$ would have a DAS28 of 3.9.

All joint assessments should be performed by a trained, independent blinded joint assessor and the same assessor should be used for all assessments during the trial, if possible $57,58,59$. Assessor training with ongoing inter- and intrarater reliability testing (and retraining) is recommended ${ }^{60}$.

ACR functional classification. Recommendation: Participant must be ambulatory.

The 1991 ACR functional classification criterion is too restrictive because it excludes patients needing any assistance with usual activities of daily living ${ }^{61}$. We recommend use of the original ACR functional class criteria ${ }^{62}$ or exclude only bedridden subjects $45,63,64,65$.

Disease duration. Recommendations: (a) minimum disease duration for established RA: 6 months or more after symptom onset; (b) minimum disease duration for early RA: 8 to 12 weeks after symptom onset and 6 weeks after symptom onset if protocol is targeting very early RA; (c) maximum disease duration for early RA: 1 to 2 years after symptom onset.

Disease duration continues to be a negotiated category as current efforts focus on identifying patients at the earliest possible timepoint and examining the importance of potential risk factors with radiographic disease progression. The ACR has stratified its treatment guidelines using a minimum duration of 6 months ${ }^{66}$ and this limit has been used in recent trials $^{45,47,67,68,69,70,71,72}$. Duration of symptoms has recently been defined as patient self-report of the duration of signs and symptoms of synovitis of joints that are clinically involved at the time of assessment, regardless of treatment status $^{22}$. Very few recent RCT limited the length of the disease duration unless they were targeted to early $\mathrm{RA}^{25,26}$.

Concomitant RA medications at baseline. Recommendations: (a) Phase I: stable MTX or monotherapy without MTX background; (b) Phase II: stable MTX or MTX plus hydroxychloroquine; and (c) Phase III to IV: stable DMARD (monotherapy or combination).

There are 3 distinct cohorts of patients with RA available for clinical trials: patients who are naive to DMARD therapy, DMARD-inadequate responders and biologic-inadequate responders ${ }^{73}$.

Some trials, particularly those in very early RA, will continue to require patients to be DMARD-naive and/or not receiving any DMARD at baseline ${ }^{25,26,53}$.

Methotrexate (MTX) add-on trials. Recommendations: Duration of MTX at baseline: (a) For a 3-month primary endpoint: 12 weeks of stable MTX. (b) For a 6-month primary endpoint: 8 weeks of stable MTX.

MTX monotherapy, or in combination with other DMARD, is now often the standard of care. Because patients can improve taking MTX over 3 to 6 months, the

Personal non-commercial use only. The Journal of Rheumatology Copyright @ 2011 . All rights reserved. 
dose and route of administration should be stable to avoid what could be a high placebo response $\mathrm{s}^{54,74}$. We recommend that patients should have received some dose of MTX for at least 6 months prior to trial enrollment. To truly identify the MTX-inadequate responders, baseline MTX dosing should be 20 to $25 \mathrm{mg} /$ week (oral or subcutaneous) if tolerated and supported by local guidelines ${ }^{75,76}$. Doses $<20 \mathrm{mg} /$ week are acceptable to avoid intolerance and toxicity. Optimal dosing ranges and options for managing common side effects are now outlined in the most current treatment guidelines $66,77,78,79,80$. Folate supplementation should be used according to local guidelines ${ }^{76,81}$.

Other DMARD add-on trials. Recommendation: If DMARD other than MTX are allowed to continue, the patient should have been taking each DMARD for at least 12 weeks and receiving a stable dose within local treatment guidelines for at least 4 weeks prior to initiation of study drug.

Patients taking a stable single or multiple DMARD should be allowed entry into trials unless there is a concern that there could be an unwanted drug interaction with a specific DMARD and the study medication. There are some people who cannot tolerate MTX or have contraindications to its use and they are often excluded from RA trials. In a real-world Canadian RCT only $70 \%$ of patients were currently taking MTX when a biologic was initiated ${ }^{82}$. Newer trials have allowed the inclusion of other or combination stable DMARD as concomitant therapies and have demonstrated the efficacy of other DMARD in the optimal treatment of RA, in addition to MTX and biologics. Katchamart, et $a l^{83}$ recently completed a systematic review of RCT comparing MTX monotherapy vs MTX combined with other nonbiologic DMARD in adult RA populations. Nineteen trials, totaling 2025 patients, were reviewed. Ma, et al ${ }^{84}$ completed a metaanalysis of RCT to determine how combination DMARD therapies (including some biologics) plus MTX affect clinical and radiological outcomes compared to MTX therapy alone in early active RA. Fifteen RCT, totaling 4200 randomized patients, were included in the review. The CRRC supports the use of stable combination DMARD as opposed to discontinuing all DMARD except MTX. However, stratification for MTX alone vs other DMARD alone or in combination should occur to correct for potentially different response rates and toxicities between the underlying treatment groups. We recommend against the use of combination MTX and leflunomide in a clinical trial due to the increased risk of side effects ${ }^{85}$ and the recent finding from the Canadian RA treatment guidelines team that it has no added benefit relative to other DMARD combinations ${ }^{79}$.

Oral corticosteroids at baseline. Recommendation: If low-dose oral corticosteroids are allowed, the patient must be on stable dosing for at least 4 weeks prior to initiation of study drug. "Low-dose" is considered $<10 \mathrm{mg} /$ day.

Low-dose oral corticosteroids have been proven an effective therapy in the treatment of signs and symptoms of RA and may also improve radiographic outcomes ${ }^{86,87,88}$. RA RCT allow the use of stable low-dose oral corticosteroids as a concomitant therapy $26,38,39,42,45,46,47,55,69,72$. Hoes, et al $^{88}$ have recently reviewed RCT of glucocorticoid cotherapy with DMARD in RA, and summarized the evidence to support low to medium doses (well under $10 \mathrm{mg} /$ day). If a remission criterion stricter than the DAS remission is to be a study outcome, especially in trials of early RA, a mechanism will be required to taper and discontinue steroids. Stratification by use of steroids at baseline should likely be performed as the treatment effect could be different (as well as the severity of subjects taking steroids).

Exclusion criteria. Studies have suggested that the majority of exclusion criteria are not directly related to drug safety, but they impair trial recruitment and generalizability ${ }^{89}$. In most trials, patients with significant comorbidities, older age, and past cancer have been excluded ${ }^{90}$. It is important to balance safety with generalizability of the data from an ideal population to the real world. Only exclusion criteria that address the safety of a product should be considered, but not necessarily past treatments or remote (cured) cancers.

Study design.

Rescue therapy. Recommendations: (a) rescue to the active drug should be allowed if the trial continues longer than 12 weeks, with criteria for rescue defined as failure of the patient to improve TJC and SJC by $20 \%$ or more or a DAS28 response less than 1.2. Failure to achieve an ACR20 criteria response should not be used as a rescue criterion; (b) change to active agent in Phase II and III trials.

Improvements in overall outcomes for patients over the past decade may be as attributable to the strategy of treatment as to the agent used ${ }^{91}$. Rescue of participants with an inadequate response to their current regimen within an RCT is increasingly being included as a standard component of study design. However, the timing of rescue, and how it is measured, may affect withdrawal rates from trials, and these results may be misinterpreted by those conducting systematic reviews and guideline development. For example, in 2 RCT of certolizumab pegol the majority of participants receiving placebo $(62.8 \%$ and $79.5 \%)$ were rescued at Week $16^{68,72}$. Of significance, the criteria for rescue likely accounted for the high withdrawal rate in these 2 studies. Thus, instead of the criterion of failing to achieve a $20 \%$ improvement in the TJC and SJC, participants failing to achieve an ACR20 response were rescued. Upon further analysis, the primary reason for failing to achieve the ACR20 response related to patient-reported outcomes, not physician or laboratory outcomes (E.C. Keystone, personal communication). This result is consistent with other studies of ACR20 nonresponders ${ }^{92}$. It is also important to note that if there is rescue therapy at 12 weeks, then the maximal ACR response scores could be blunted, as even with fast-acting agents ACR70 improvements usually occur beyond 12 weeks ${ }^{93}$.

Despite the significant outlay of time and resources to

Personal non-commercial use only. The Journal of Rheumatology Copyright $\odot$ 2011. All rights reserved. 
complete RCT, CADTH, a national body that provides Canada's federal, provincial, and territorial healthcare decision-makers with evidence-based information about the effectiveness and efficiency of drugs, recently excluded certolizumab pegol trials from its metaanalysis and subsequent recommendations for biologics use in Canada ${ }^{94}$. CADTH excluded the certolizumab pegol trials because of the high rate of withdrawals, without fully taking into account the finding that the rescue strategy, and not traditional reasons for withdrawal, influenced the primary results (CRRC, personal communication). Adaptive designs and clinical trial efficiency are considered a current challenge for rheumatology trials $^{73,95}$.

A high rate of withdrawal is of particular concern when regulatory agencies require radiographic evidence at 52 weeks in order to demonstrate proof of structural improvements in RA trials ${ }^{96,97}$. In countries such as Canada, defined options for rescue (either blinded or open-label) are increasingly considered necessary by ethics review boards (CRRC, personal communication). In an era of early, rapidly escalated treatment and tight monitoring, it may be time to reassess the optimal use and timing of radiographic outcomes in the context of emerging trial designs ${ }^{98,99,100}$.

Intraarticular steroid rescue for trials of 6 months or longer. Recommendations: (a) 1 large joint: methylprednisolone acetate $40 \mathrm{mg}$ to $80 \mathrm{mg}$, triamcinolone acetonide $40 \mathrm{mg}$, and triamcinolone hexacetonide $40 \mathrm{mg}$ may be given more than 8 weeks from significant endpoints or assessments; and (b) eliminate the injected joint from both clinical and radiographic assessment if intraarticular steroids are given at any time after baseline.

Limited intraarticular injections have been added to RCT as a strategy to retain patients in the trial. The steroid affects the injected joint but also has a systemic impact; a single injection may have a substantial effect on the disease activity state for several weeks ${ }^{88,101}$.

Longterm extension. Recommendation: Phase IIb, Phase III (and potentially some Phase IV) trials: Participants should be eligible for longterm extension if the experimental product moves forward in development with no safety issues for the patient after the trial closes. The extension should occur at a timepoint most appropriate for the investigational drug to ensure optimal safety and effectiveness for the patient. A statement to this effect should be included in the consent form.

Industry sponsors are increasingly providing open-label access to new drugs after primary endpoints are assessed under randomized and blinded conditions. The utility of open-label studies is currently being addressed in the literature ${ }^{102,103,104}$. The extension should be timed to ensure optimal safety and effectiveness for trial participants while not jeopardizing blinding or measurement of primary endpoints. Access to efficacious medications that are otherwise unavailable or unaffordable can be an important motivator for patients to participate in clinical trials ${ }^{105,106}$. A CRRC needs assessment found that recruitment to RCT without an open-label extension is becoming quite difficult (CRRC, personal communication).

Most regulatory bodies require longterm safety and effectiveness data prior to licensing a new therapeutic agent ${ }^{96,97}$. In addition, longterm experience is gained by the investigators for the product and provides important information on durability (sustained or improved response, dropout rate due to loss of effectiveness or adverse events), so the risk-to-benefit of a product can be determined over a longer period of time.

\section{DISCUSSION}

In recent years, RCT in rheumatology have become increasingly complicated. At the same time, participant recruitment at established rheumatology research sites is increasingly difficult. This situation has created an urgent impetus to modify traditional RCT design. This crisis has been addressed in the literature $28,49,50,56,73,74,93,95,107,108,109,110$, $111,112,113,114,115,116,117,118,119$. However, there has been little effect of this body of work on RCT designed and sponsored by the pharmaceutical industry and required by regulators and payers.

The changes that we have outlined should increase the pool of appropriate trial participants by taking into consideration the baseline clinical characteristics of current patients with RA. There is now adequate literature to support these changes based on more recent studies that have generated similar clinical outcomes compared to more standard designs. More studies with these designs are needed to demonstrate comparable radiographic outcomes.

Of significance, the characteristics of patients entering trials with current designs generate results that do not reflect those of clinical practice in the real world $28,49,50,112,113$, $114,115,116,117,118,119$. Thus, the lower disease activity of patients in practice may not result in treatment responses (as determined by ACR or EULAR DAS responses) as high as those in clinical trials, but do improve the proportion of patients achieving a low disease state or remission. It is time to adapt clinical trial outcomes to reflect disease states achieved, rather than treatment responses. The use of less stringent inclusion criteria in trials in concert with changes in primary outcomes would go a long way toward improving the generalizability of clinical trials to clinical practice in countries with established rheumatology infrastructure, while at the same time improving the participation of countries where therapies are most utilized.

We also proposed changes in trial design that would enhance the interpretation of the results. Among them is assuring stability of background DMARD to avoid a high placebo response rate, and utilizing higher doses and parenterally administered MTX to identify true MTX inadequate responders. We discussed the challenges of rescue strategies. Such strategies are important to enhance patient Personal non-commercial use only. The Journal of Rheumatology Copyright $\odot$ 2011. All rights reserved. 
acceptance of participation in a study but may have had unforeseen consequences of inappropriately high withdrawal rates leading to difficulties in the interpretation of results. In particular, short duration on placebo makes the interpretation of radiographic data very difficult and the timing of radiographic endpoints and the interpretation of their clinical significance may need to be reevaluated. It is a useful reminder that the original US Food and Drug Administration guidance document to industry for the acceptance of an indication for prevention of radiographic progression suggested placebo-controlled trials of 2 to 5 years ${ }^{96}$.

We have not addressed many other barriers to clinical trial recruitment such as changing procedures to make trials more attractive to patients. CRRC members have reported that patients who are approached about enrolling in a clinical trial are often frightened by highly legalistic consent forms and inordinate time commitments (CRRC, personal communication). Increasing the number of centers doing trials could improve recruitment, but becoming a successful trialist can be a daunting and expensive task. Nevertheless, if the expertise in conducting clinical trials that has developed over the past 2 decades in established sites is to remain engaged, changes have to be considered. There are many important therapeutic questions remaining to be answered. A move to innovative trial designs is currently being discussed to address a similar crisis in cancer research ${ }^{15}$.

There is an urgent need to modify RCT inclusion criteria and other study design features such as primary outcomes to better reflect the current characteristics of people living with RA in the countries where the new drugs will be used. Regulators, scientists, and others involved must address this crisis before we lose our capacity to participate in clinical trials that are relevant to the optimal treatment of our patients.

\section{ACKNOWLEDGMENT}

The authors thank Linda Bennett for project supervision and Annette Wilkins for research support. Additional support was provided by Liz Croatto, Lina Gazizova, Amanda Himmel, M. Shah Newaz, Ashley Bonner, and Pooneh Akhavan.

\section{REFERENCES}

1. Glickman SW, McHutchison JG, Peterson ED, Cairns CB, Harrington RA, Califf RM, et al. Ethical and scientific implications of the globalization of clinical research. N Engl J Med 2009;360:816-23.

2. Thiers FA, Sinskey AJ, Berndt ER. Trends in the globalization of clinical trials. Nat Rev Drug Disc 2008;7:13-4.

3. Karlberg JPE. Globalization of sponsored clinical trials. Nat Rev Drug Disc 2008;7:458.

4. Devasenapathy N, Singh K, Prabhakaran D. Conduct of clinical trials in developing countries: a perspective. Curr Opin Cardiol 2009:24:295-300

5. Stough WG, Zannad F, Pitt B, Goldstein S. Globalization of cardiovascular clinical research: the balance between meeting medical needs and maintaining scientific standards. Am Heart J 2007;154:232-8.

6. Keystone EC, Genovese MC, Klareskog L, Hsia EC, Hall ST, Miranda PC, et al. Golimumab, a human antibody to tumour necrosis factor alpha given by monthly subcutaneous injections, in active rheumatoid arthritis despite methotrexate therapy: the GO-FORWARD Study. Ann Rheum Dis 2009;68:789-96.

7. Keystone E, Genovese MC, Klareskog L, Hsia EC, Hall S, Miranda PC, et al. Golimumab in patients with active rheumatoid arthritis despite methotrexate therapy: 52-week results of the GO-FORWARD study. Ann Rheum Dis 2010;69:1129-35.

8. Emery P, Rigby WFC, Tak PP, Dorner T, Olech E, Genovese MC, et al. Serious infections with ocrelizumab in rheumatoid arthritis: Pooled results from double-blind periods of the ocrelizumab Phase III RA Program [abstract]. Arthritis Rheum 2010;62 Suppl:414.

9. Mody GM, Cardiel MH. Challenges in the management of rheumatoid arthritis in developing countries. Best Pract Res Clin Rheumatol 2008;22:621-41.

10. Brooks PM. The burden of musculoskeletal disease - a global perspective. Clin Rheumatol 2006;25:778-81

11. Darmawan J. Recommendations from the Community Oriented Program for Control of Rheumatic Disease for data collection for the measurement and monitoring of health in developing countries. Clin Rheumatol 2007;26:853-7.

12. Woolf AD, Brooks P, Akesson K, Mody GM. Prevention of musculoskeletal conditions in the developing world. Best Pract Res Clin Rheumatol 2008;22:759-72.

13. Massardo L, Suárez-Almazor ME, Cardiel MH, Nava A, Levy RA Laurindo I, et al. Management of patients with rheumatoid arthritis in Latin America: a consensus position paper from Pan-American League of Associations of Rheumatology and Grupo Latino Americano De Estudio De Artritis Reumatoide. J Clin Rheumatol 2009;15:203-10.

14. Sokka T, Kautiainen H, Pincus T, Toloza S, da Rocha Castelar Pinheiro G, Lazovskis J, et al. Disparities in rheumatoid arthritis disease activity according to gross domestic product in 25 countries in the QUEST-RA database. Ann Rheum Dis 2009;68:1666-72.

15. Young RC. Cancer clinical trials - a chronic but curable crisis. N Engl J Med 2010;363:306-9.

16. International Conference on Harmonisation of Technical Requirements for Registration of Pharmaceuticals for Human Use. Guideline for good clinical practice E6 (R1). ICH harmonised tripartite guideline, 1996. ICH, Geneva, Switzerland.

17. Fink A, Kosecoff J, Chassin M, Brook RH. Consensus methods: characteristics and guidelines for use. Am J Public Health 1984;74:979-83.

18. Arksey H, O'Malley L. Scoping studies: towards a methodologica framework. Int J Soc Res Meth 2005;8:19-32.

19. Felson DT, Anderson JJ, Boers M, Bombardier C, Furst D, Goldsmith C, et al. American College of Rheumatology. Preliminary definition of improvement in rheumatoid arthritis. Arthritis Rheum 1995;38:727-35.

20. van Gestel AM, Prevoo ML, van 't Hof MA, van Rijswijk MH, van de Putte LB, van Riel PL. Development and validation of the European League Against Rheumatism response criteria for rheumatoid arthritis. Comparison with the preliminary American College of Rheumatology and the World Health Organization/International League Against Rheumatism criteria. Arthritis Rheum 1996;39:34-40.

21. Arnett FC, Edworthy SM, Bloch DA, McShane DJ, Fries JF, Cooper NS, et al. The American Rheumatism Association 1987 revised criteria for the classification of rheumatoid arthritis. Arthritis Rheum 1988;31:315-24.

22. Aletaha D, Neogi T, Silman AJ, Funovits J, Felson DT, Bingham CO 3rd, et al. 2010 rheumatoid arthritis classification criteria: an American College of Rheumatology/ European League Against Rheumatism collaborative initiative. Ann Rheum Dis 2010;69:1580-8.

23. Bykerk VP, Boire G, Haraoui B, Hitchon CA, Keystone EC, Thorne JC, et al. The Revised 2010 ACR/EULAR Diagnostic Criteria for 
Rheumatoid Arthritis identify many more patients who are eligible for treatment and for clinical trials [abstract]. Arthritis Rheum 2010;62 Suppl:S274.

24. Prevoo ML, van 't Hof MA, Kuper HH, van Leeuwen MA, van de Putte LB, van Riel PL. Modified disease activity scores that include twenty-eight-joint counts. Development and validation in a prospective longitudinal study of patients with rheumatoid arthritis. Arthritis Rheum 1995;38:44-8.

25. Emery P, Breedveld FC, Hall S, Durez P, Chang DJ, Robertson D, et al. Comparison of methotrexate monotherapy with a combination of methotrexate and etanercept in active, early, moderate to severe rheumatoid arthritis (COMET): a randomised, double-blind, parallel treatment trial. Lancet 2008;372:375-82.

26. van Vollenhoven RF, Ernestam S, Geborek P, Petersson IF, Cöster L, Waltbrand E, et al. Addition of infliximab compared with addition of sulfasalazine and hydroxychloroquine to methotrexate in patients with early rheumatoid arthritis (Swefot trial): 1-year results of a randomised trial. Lancet 2009;374:459-66.

27. Landewé RB, Houbiers JG, van den Bosch F, in't Hout J, Verschueren PC, Meijerink JH, et al. Intranasal administration of recombinant human cartilage glycoprotein-39 as a treatment for rheumatoid arthritis: a phase II, multicentre, double-blind, randomised, placebo-controlled, parallel-group, dose-finding trial. Ann Rheum Dis 2010;69:1655-9.

28. Kingsley GH, Khoshaba B, Smith CM, Choy EH, Scott DL. Are clinical trials in rheumatoid arthritis generalizable to routine practice? A re-evaluation of trial entry criteria. Rheumatology 2005;44:629-32.

29. Pincus T, Sokka T. Laboratory tests to assess patients with rheumatoid arthritis: advantages and limitations. Rheum Dis Clin North Am 2009;35:731-4, vi-vii.

30. Abelson B, Sokka T, Pincus T. Declines in erythrocyte sedimentation rates in patients with rheumatoid arthritis over the second half of the 20th century. J Rheumatol 2009;36:1596-9.

31. Wolfe F. The many myths of erythrocyte sedimentation rate and C-reactive protein. J Rheumatol 2009;36:1568-9.

32. Wolfe F, Pincus T. The level of inflammation in rheumatoid arthritis is determined early and remains stable over the longterm course of the illness. J Rheumatol 2001;28:1817-24.

33. Weinblatt ME, Kavanaugh A, Genovese MC, Musser TK, Grossbard EB, Magilavy DB. An oral spleen tyrosine kinase (Syk) inhibitor for rheumatoid arthritis. N Engl J Med 2010;363:1303-12.

34. Wells GA, Boers M, Li T, Tugwell PS. Investigating the validity of the minimal disease activity state for patients with rheumatoid arthritis treated with abatacept. J Rheumatol 2009;36:260-5.

35. Hensor EM, Emery P, Bingham SJ, Conaghan PG. Discrepancies in categorizing rheumatoid arthritis patients by DAS-28(ESR) and DAS-28(CRP): Can they be reduced? Rheumatology 2010;49:1521-9.

36. Westhovens R, Robles M, Ximenes AC, Nayiager S, Wollenhaupt J, Durez $\mathrm{P}$, et al. Clinical efficacy and safety of abatacept in methotrexate-naive patients with early rheumatoid arthritis and poor prognostic factors. Ann Rheum Dis 2009;68:1870-7.

37. Emery P, Durez P, Dougados M, Legerton CW, Becker JC, Vratsanos G, et al. Impact of T-cell costimulation modulation in patients with undifferentiated inflammatory arthritis or very early rheumatoid arthritis: a clinical and imaging study of abatacept (the ADJUST trial). Ann Rheum Dis 2010;69:510-6.

38. Kremer JM, Genant HK, Moreland LW, Russell AS, Emery P, Abud-Mendoza C, et al. Effects of abatacept in patients with methotrexate-resistant active rheumatoid arthritis: a randomized trial. Ann Intern Med 2006;144:865-76.

39. Schiff M, Keiserman M, Codding C, Songcharoen S, Berman A, Nayiager S, et al. Efficacy and safety of abatacept or infliximab vs placebo in ATTEST: a phase III, multi-centre, randomised, double-blind, placebo-controlled study in patients with rheumatoid arthritis and an inadequate response to methotrexate. Ann Rheum
Dis 2008;67:1096-103.

40. Schiff M. Abatacept treatment for rheumatoid arthritis. Rheumatology 2011;50:437-49.

41. Patel AM, Moreland LW. Interleukin-6 inhibition for treatment of rheumatoid arthritis: a review of tocilizumab therapy. Drug Des Devel Ther 2010;4:263-78.

42. Smolen JS, Beaulieu A, Rubbert-Roth A, Ramos-Remus C, Rovensky J, Alecock E, et al. Effect of interleukin-6 receptor inhibition with tocilizumab in patients with rheumatoid arthritis (OPTION study): a double-blind, placebo-controlled, randomised trial. Lancet 2008;371:987-97.

43. Genovese MC, McKay JD, Nasonov EL, Mysler EF, da Silva NA, Alecock E, et al. Interleukin-6 receptor inhibition with tocilizumab reduces disease activity in rheumatoid arthritis with inadequate response to disease-modifying antirheumatic drugs: the tocilizumab in combination with traditional disease-modifying antirheumatic drug therapy study. Arthritis Rheum 2008;58:2968-80.

44. Fleischmann R, Burgos-Vargas R, Ambs P, Alecock E, Kremer J. LITHE: Tocilizumab inhibits radiographic progression and improves physical function in rheumatoid arthritis (RA) patients (pts) at 2 yrs with increasing clinical efficacy over time [abstract] Arthritis Rheum 2009;60 Suppl:637.

45. Nishimoto N, Miyasaka N, Yamamoto K, Kawai S, Takeuchi T, Azuma J, et al. Study of active controlled tocilizumab monotherapy for rheumatoid arthritis patients with an inadequate response to methotrexate (SATORI): significant reduction in disease activity and serum vascular endothelial growth factor by IL-6 receptor inhibition therapy. Mod Rheumatol 2009;19:12-9.

46. Jones G, Sebba A, Gu J, Lowenstein MB, Calvo A, Gomez-Reino JJ, et al. Comparison of tocilizumab monotherapy versus methotrexate monotherapy in patients with moderate to severe rheumatoid arthritis: the AMBITION study. Ann Rheum Dis 2010;69:88-96.

47. Emery P, Keystone E, Tony HP, Cantagrel A, van Vollenhoven R, Sanchez A, et al. IL-6 receptor inhibition with tocilizumab improves treatment outcomes in patients with rheumatoid arthritis refractory to anti-tumour necrosis factor biologicals: results from a 24-week multicentre randomised placebo-controlled trial. Ann Rheum Dis 2008;67:1516-23.

48. Pincus T, Sokka T, Chung CP, Cawkwell G. Declines in number of tender and swollen joints in patients with rheumatoid arthritis seen in standard care in 1985 versus 2001: possible considerations for revision of inclusion criteria for clinical trials. Ann Rheum Dis 2006;65:878-83.

49. Akhavan P, Bykerk V, Sun Y, Boire G, Pope J, Haraoui B, et al. "Liberal" (easier to achieve) compared to "standard" entry criteria improves trial recruitment in a real world practice. Results from the Canadian Early Rheumatoid Arthritis Cohort (CATCH) [abstract]. London: EULAR Scientific Programme. EULAR 2011: SAT0390.

50. Greenberg JD, Kishimoto M, Strand V, Cohen SB, Olenginski TP, Harrington $\mathrm{T}$, et al. Tumor necrosis factor antagonist responsiveness in a United States rheumatoid arthritis cohort. Am J Med 2008;121:532-8.

51. Smolen JS, Breedveld FC, Eberl G, Jones I, Leeming M, Wylie GL, et al. Validity and reliability of the twenty-eight-joint count for the assessment of rheumatoid arthritis activity. Arthritis Rheum 1995;38:38-43.

52. Lu LJ, Bao CD, Dai M, Teng JL, Fan W, Du F, et al. Multicenter, randomized, double-blind, controlled trial of treatment of active rheumatoid arthritis with T-614 compared with methotrexate. Arthritis Rheum 2009;61:979-87.

53. Emery P, Fleischmann RM, Moreland LW, Hsia EC, Strusberg I, Durez P, et al. Golimumab, a human anti-tumor necrosis factor alpha monoclonal antibody, injected subcutaneously every four weeks in methotrexate-naive patients with active rheumatoid arthritis: twenty-four-week results of a phase III, multicenter, randomized, double-blind, placebo-controlled study of golimumab 
before methotrexate as first-line therapy for early-onset rheumatoid arthritis. Arthritis Rheum 2009;60:2272-83.

54. Kremer J, Ritchlin C, Mendelsohn A, Baker D, Kim L, Xu Z, et al. Golimumab, a new human anti-tumor necrosis factor alpha antibody, administered intravenously in patients with active rheumatoid arthritis: Forty-eight-week efficacy and safety results of a phase III randomized, double-blind, placebo-controlled study. Arthritis Rheum 2010;62:917-28.

55. Smolen JS, Kay J, Doyle MK, Landewé R, Matteson EL, Wollenhaupt J, et al. Golimumab in patients with active rheumatoid arthritis after treatment with tumour necrosis factor alpha inhibitors (GO-AFTER study): a multicentre, randomised, double-blind, placebo-controlled, phase III trial. Lancet 2009;374:210-21.

56. Zhang B, Lavalley M, Felson DT. The sensitivity to change for lower disease activity is greater than for higher disease activity in rheumatoid arthritis trials. Ann Rheum Dis 2009;68:1255-9.

57. U.S. Department of Health and Human Services. Clinical development programs for drugs, devices and biological products for the treatment of rheumatoid arthritis (RA). Washington, DC: Food and Drug Administration Center for Drug Evaluation and Research; Arthritis Advisory Committee; Guidance for Industry; volume II. February 1997.

58. Sokka T. How should rheumatoid arthritis disease activity be measured today and in the future in clinical care? Rheum Dis Clin North Am 2010;36:243-57.

59. Pincus T. Limitations of a quantitative swollen and tender joint count to assess and monitor patients with rheumatoid arthritis. Bull NYU Hosp Jt Dis 2008;66:216-23.

60. Bell MJ, Lineker SC, Wilkins AL, Goldsmith CH, Badley EM. A randomized controlled trial to evaluate the efficacy of community based physical therapy in the treatment of people with rheumatoid arthritis. J Rheumatol 1998;25:231-7.

61. Hochberg MC, Chang RW, Dwosh I, Lindsey S, Pincus T, Wolfe F. The American College of Rheumatology 1991 revised criteria for the classification of global functional status in rheumatoid arthritis. Arthritis Rheum 1992;35:498-502.

62. Steinbrocker O, Traeger $\mathrm{CH}$, Batterman RC. Therapeutic criteria in rheumatoid arthritis. J Am Med Assoc 1949;140:659-62.

63. Cohen SB, Cheng TT, Chindalore V, Damjanov N, Burgos-Vargas $\mathrm{R}$, Delora P, et al. Evaluation of the efficacy and safety of pamapimod, a p38 MAP kinase inhibitor, in a double-blind, methotrexate-controlled study of patients with active rheumatoid arthritis. Arthritis Rheum 2009;60:335-44.

64. Crilly MA, Macdonald AG, Williams DJ, Kumar V, Clark HJ. Constitutional symptoms at the onset of rheumatoid arthritis and subsequent arterial stiffness. Clin Rheumatol 2010;29:1113-9.

65. Hayashibara M, Hagino H, Katagiri H, Okano T, Okada J, Teshima $\mathrm{R}$. Incidence and risk factors of falling in ambulatory patients with rheumatoid arthritis: a prospective 1-year study. Osteoporos Int 2010;21:1825-33

66. Saag KG, Teng GG, Patkar NM, Anuntiyo J, Finney C, Curtis JR, et al. American College of Rheumatology. American College of Rheumatology 2008 recommendations for the use of nonbiologic and biologic disease-modifying antirheumatic drugs in rheumatoid arthritis. Arthritis Rheum 2008:59:762-84.

67. Emery P, Deodhar A, Rigby WF, Isaacs JD, Combe B, Racewicz AJ, et al. Efficacy and safety of different doses and retreatment of rituximab: a randomised, placebo-controlled trial in patients who are biological naive with active rheumatoid arthritis and an inadequate response to methotrexate (Study Evaluating Rituximab's Efficacy in MTX iNadequate rEsponders (SERENE)). Ann Rheum Dis 2010;69:1629-35.

68. Keystone E, van der Heijde D, Mason D Jr, Landewé R, van Vollenhoven R, Combe B, et al. Certolizumab pegol plus methotrexate is significantly more effective than placebo plus methotrexate in active rheumatoid arthritis: findings of a fifty-two-week, phase III, multicenter, randomized, double-blind, placebo-controlled, parallel-group study. Arthritis Rheum 2008:58:3319-29.

69. Østergaard M, Baslund B, Rigby W, Rojkovich B, Jorgensen C, Dawes PT, et al. Ofatumumab, a human anti-CD20 monoclonal antibody, for treatment of rheumatoid arthritis with an inadequate response to one or more disease-modifying antirheumatic drugs: results of a randomized, double-blind, placebo-controlled, phase I/II study. Arthritis Rheum 2010;62:2227-38.

70. Damjanov N, Kauffman RS, Spencer-Green GT. Efficacy, pharmacodynamics, and safety of VX-702, a novel p38 MAPK inhibitor, in rheumatoid arthritis: results of two randomized, double-blind, placebo-controlled clinical studies. Arthritis Rheum 2009;60:1232-41.

71. Fleischmann R, Vencovsky J, van Vollenhoven RF, Borenstein D, Box J, Coteur G, et al. Efficacy and safety of certolizumab pegol monotherapy every 4 weeks in patients with rheumatoid arthritis failing previous disease-modifying antirheumatic therapy: the FAST4WARD study. Ann Rheum Dis 2009;68:805-11.

72. Smolen J, Landewé RB, Mease P, Brzezicki J, Mason D, Luijtens $\mathrm{K}$, et al. Efficacy and safety of certolizumab pegol plus methotrexate in active rheumatoid arthritis: the RAPID 2 study. A randomised controlled trial. Ann Rheum Dis 2009;68:797-804.

73. Schwieterman WD. Issues in the design of new clinical trials for rheumatoid arthritis therapeutics. Nat Clin Pract Rheumatol 2008;4:641-8

74. Strand V, Sokolove J. Randomized controlled trial design in rheumatoid arthritis: the past decade. Arthritis Res Ther 2009;11:205

75. Visser K, van der Heijde D. Optimal dosage and route of administration of methotrexate in rheumatoid arthritis: a systematic review of the literature. Ann Rheum Dis 2009;68:1094-9.

76. Visser K, Katchamart W, Loza E, Martinez-Lopez JA, Salliot C, Trudeau J, et al. Multinational evidence-based recommendations for the use of methotrexate in rheumatic disorders with a focus on rheumatoid arthritis: integrating systematic literature research and expert opinion of a broad international panel of rheumatologists in the 3E Initiative. Ann Rheum Dis 2009;68:1086-93.

77. National Institute for Health and Clinical Excellence (NICE). Rheumatoid arthritis: The management of rheumatoid arthritis in adults. London: National Collaborating Centre for Chronic Conditions; NICE clinical guideline 79. February 2009.

78. Luqmani R, Hennell S, Estrach C, Basher D, Birrell F, Bosworth A, et al. British Society for Rheumatology and British Health Professionals in Rheumatology guideline for the management of rheumatoid arthritis (after the first 2 years). Rheumatology 2009;48:436-9.

79. Bykerk V, Akhavan P, Hazlewood GS, Schieir O, Dooley A, Haraoui B, et al. Canadian recommendations for the pharmacological management of rheumatoid arthritis with traditional and biologic disease modifying anti-rheumatic drugs. J Rheumatol 2011 [in press].

80. Smolen JS, Landewé R, Breedveld FC, Dougados M, Emery P, Gaujoux-Viala C, et al. EULAR recommendations for the management of rheumatoid arthritis with synthetic and biological disease-modifying antirheumatic drugs. Ann Rheum Dis 2010;69:964-75.

81. Whittle SL, Hughes RA. Folate supplementation and methotrexate treatment in rheumatoid arthritis: a review. Rheumatology 2004;43:267-71.

82. Haraoui BP, Pope J, Thorne JC, Sampalis J, Psaradellis F. Regional differences between patients with rheumatoid arthritis (RA) in Canada at initiation of adalimumab treatment in Canada: Results of the Optimization of Humira Trial [abstract]. J Rheumatol 2009;36:2578.

83. Katchamart W, Trudeau J, Phumethum V, Bombardier C. Methotrexate monotherapy versus methotrexate combination therapy with non-biologic disease modifying anti-rheumatic drugs 
for rheumatoid arthritis. Cochrane Database Syst Rev 2010;4:CD008495.

84. Ma MH, Kingsley GH, Scott DL. A systematic comparison of combination DMARD therapy and tumour necrosis inhibitor therapy with methotrexate in patients with early rheumatoid arthritis. Rheumatology 2010;49:91-8.

85. The European Agency for the Evaluation of Medicinal Products. Post-authorisation evaluation of medicines for human use. EMEA public statement on leflunomide (Arava) - severe and serious hepatic reactions. Document reference EMEA/H/5611/01/en. London: EMEA; 12 March 2001.

86. Gorter SL, Bijlsma JW, Cutolo M, Gomez-Reino J, Kouloumas M, Smolen JS, et al. Current evidence for the management of rheumatoid arthritis with glucocorticoids: a systematic literature review informing the EULAR recommendations for the management of rheumatoid arthritis. Ann Rheum Dis 2010;69:1010-4.

87. Kirwan JR, Bijlsma JW, Boers M, Shea BJ. Effects of glucocorticoids on radiological progression in rheumatoid arthritis. Cochrane Database Syst Rev 2007;1:CD006356.

88. Hoes JN, Jacobs JW, Buttgereit F, Bijlsma JW. Current view of glucocorticoid co-therapy with DMARDs in rheumatoid arthritis. Nat Rev Rheumatol 2010;6:693-702.

89. Yuen SY, Pope J. Learning from past mistakes: Assessing trial quality, power and eligibility in non-renal systemic lupus erythematosus randomized controlled trials. Rheumatology 2008;47:1367-72.

90. Leber PD, Davis CS. Threats to the validity of clinical trials employing enrichment strategies for sample selection. Control Clin Trials 1998;19:178-87.

91. Sokka T, Pincus T. Rheumatoid arthritis: strategy more important than agent. Lancet 2009;374:430-2.

92. Smolen JS, Han C, Bala M, Kalden JR, van der Heijde D, Breedveld FC, et al. Evidence of radiographic benefit of treatment with infliximab plus methotrexate in rheumatoid arthritis patients who had no clinical improvement: a detailed subanalysis of data from the Anti-tumor Necrosis Factor Trial in Rheumatoid Arthritis with Concomitant Therapy study. Arthritis Rheum 2005;52:1020-30.

93. Boers M. The time has come to limit the placebo period in rheumatoid arthritis trials to 3 months: a systematic comparison of 3- and 6-month response rates in trials of biological agents. Ann Rheum Dis 2010;69:186-92.

94. Canadian Agency for Drugs and Technology in Health (CADTH), Therapeutic Review Panel. Biological response modifier agents for adults with rheumatoid arthritis. Ottawa: CADTH; July 2010. [Internet. Accessed June 9, 2011.] Available from: http://www.cadth.ca/en/search?q=biological+response

95. Fransen J, van Riel PL. Are better endpoints and better design of clinical trials needed? Best Pract Res Clin Rheumatol 2004; 18:97-109.

96. US Department of Health and Human Services, Food and Drug Administration, Guidance for Industry: Clinical development programs for drugs, devices, and biological products for the treatment of rheumatoid arthritis. Rockville, MD: FDA; 1999.

97. The European Agency for the Evaluation of Medicinal Products. Committee for Proprietary Medicinal Products. Evaluation of medicines for human use: points to consider on clinical investigation of medicinal products other than NSAIDS for treatment of rheumatoid arthritis. CPMP/EWP/556/95 rev 1/Final. London; 2003.

98. Yazici Y, Sokka T, Pincus T. Radiographic measures to assess patients with rheumatoid arthritis: advantages and limitations. Rheum Dis Clin North Am 2009;35:723-9, vi.

99. Keystone EC. Clinical implications of understanding radiographic findings in relation to clinical outcomes in rheumatoid arthritis. J Rheumatol Suppl. 2009 June;82:11-6.

100. Kuriya B, Arkema EV, Bykerk VP, Keystone EC. Efficacy of initial methotrexate monotherapy versus combination therapy with a biological agent in early rheumatoid arthritis: a meta-analysis of clinical and radiographic remission. Ann Rheum Dis 2010; 69:1298-304.

101. Habib GS. Systemic effects of intra-articular corticosteroids. Clin Rheumatol 2009;28:749-56.

102. Day RO, Williams KM. Open-label extension studies: do they provide meaningful information on the safety of new drugs? Drug Saf 2007;30:93-105.

103. Treweek S, Pitkethly M, Cook J, Kjeldstrøm M, Taskila T, Johansen M, et al. Strategies to improve recruitment to randomised controlled trials. Cochrane Database Syst Rev 2010;4:MR000013.

104. Hemming K, Hutton JL, Maguire MJ, Marson AG. Open label extension studies and patient selection biases. J Eval Clin Pract 2008; $14: 141-4$.

105. Grady C. The challenge of assuring continued post-trial access to beneficial treatment. Yale J Health Policy Law Ethics 2005; 5:425-35.

106. Sofaer N, Thiessen C, Goold SD, Ballou J, Getz KA, Koski G, et al. Subjects' views of obligations to ensure post-trial access to drugs, care and information: qualitative results from the Experiences of Participants in Clinical Trials (EPIC) study. J Med Ethics 2009;35:183-8.

107. Boers M. Add-on or step-up trials for new drug development in rheumatoid arthritis: a new standard? Arthritis Rheum 2003;48:1481-3.

108. Boers M. A new design for registration trials in rheumatoid arthritis allowing secondary head-to-head comparisons with standard of care treatment including biologicals. Ann Rheum Dis 2010;69:4-6.

109. Stein CM, Pincus T. Placebo-controlled studies in rheumatoid arthritis: ethical issues. Lancet 1999;353:400-3.

110. Kavanaugh A. Ethical and practical issues in conducting clinical trials in psoriasis and psoriatic arthritis. Ann Rheum Dis 2005;64 Suppl 2:ii46-8.

111. Pincus T, Sokka T. Should contemporary rheumatoid arthritis clinical trials be more like standard patient care and vice versa? Ann Rheum Dis 2004;63 Suppl 2:ii32-ii39.

112. Rahman MU, Buchanan J, Doyle MK, Hsia E, Gathany T, Parasuraman $\mathrm{S}$, et al. Historical trends of patient characteristics in anti-TNF clinical trials for rheumatoid arthritis: an analysis of the literature over the past 16 years [abstract]. Rome: EULAR Scientific Programme. EULAR 2010: SAT0131.

113. Sokka T, Pincus T. Eligibility of patients in routine care for major clinical trials of anti-tumor necrosis factor alpha agents in rheumatoid arthritis. Arthritis Rheum 2003;48:313-8.

114. Bykerk V, Smuczek J, Boire G, Haraoui B, Hitchon C, Jamal S, et al. Early rheumatoid arthritis (ERA) trials have almost no generalizability to ERA patients: Results from a large multi-center cohort [abstract]. Arthritis Rheum 2008;58 Suppl:S161.

115. Yazici Y, Erkan D. Eligibility of rheumatoid arthritis patients seen in clinical practice for rheumatoid arthritis clinical trials: comment on the article by Sokka and Pincus. Arthritis Rheum 2003;48:3611

116. Zink A, Strangfeld A, Schneider M, Herzer P, Hierse F, Stoyanova-Scholz M, et al. Effectiveness of tumor necrosis factor inhibitors in rheumatoid arthritis in an observational cohort study: comparison of patients according to their eligibility for major randomized clinical trials. Arthritis Rheum 2006;54:3399-407.

117. Kievit W, Fransen J, Oerlemans AJ, Kuper HH, van der Laar MA, de Rooij DJ, et al. The efficacy of anti-TNF in rheumatoid arthritis, a comparison between randomised controlled trials and clinical practice. Ann Rheum Dis 2007;66:1473-8.

118. Sokka T, Pincus T. Most patients receiving routine care for rheumatoid arthritis in 2001 did not meet inclusion criteria for most recent clinical trials or American College of Rheumatology criteria for remission. J Rheumatol 2003;30:1138-46.

119. Gogus F, Yazici Y, Yazici H. Inclusion criteria as widely used for rheumatoid arthritis clinical trials: patient eligibility in a Turkish cohort. Clin Exp Rheumatol 2005;23:681-4. 